\title{
Rapid and Successful Rehabilitation and Return to Play for a Division 1 Gymnast after Treatment for Recalcitrant Lateral Epicondylosis with Ultrasound Guided Percutaneous Tenotomy
}

\author{
Bryant Walrod ${ }^{*}$
}

Department of Family and Community Medicine, Sports Medicine, The Ohio State University, Columbus, USA

\begin{abstract}
We present a novel case of an 18-year-old Division 1 college gymnast with recalcitrant lateral elbow pain. His symptoms were refractory to conservative care including NSAIDS, bracing and formal rehabilitation. This athlete had a percutaneous tenotomy performed. After a specific rehabilitation protocol, he was able to return to full Division 1 athletics two months after the procedure. This case is unique secondary to the patient being am elite athlete and his rapid return to the intensity and requirements of competing in Division 1 sports. We also define the rehabilitation protocol that we employed as this may have also influenced his rapid and complete return. This specific rehabilitation protocol may potentially guide future rehabilitation protocols after the Tenex procedure for recalcitrant lateral epicondylosis.
\end{abstract}

Keywords

Tenex, Lateral epicondylosis, Exercise protocol

\section{Key Points}

There are no established guidelines for rehabilitation after percutaneous tenotomy for chronic tendinopathies.

Successful return to play for elite level athlete 8 weeks after procedure.

Rehabilitation protocols may serve as a guide for future patients.

\section{Introduction}

Lateral epicondylagia is a common chronic condition affecting the extensor carpi radialis brevis and common wrist extensor tendons. It has been noted in both occupational and sporting activities. While this condition is often referred to lateral epicondylitis and tendinitis, histological examination would support the terms lateral epicondylosis and tendinosis. Findings of angiofibroblastic hyperplasia and collagen disarray indicate a poorly healing process rather than an acutely inflamed process of the tendon [1]. Secondary to this, alternative treatments to cortisone have been explored. In fact, there are a multitude of treatments proposed for this condition including but not limited to pro-inflammatory injections, bracing, rehabilitation, shock wave therapy and surgery. There are varying degrees of success of these treatments with no "gold standard" being identified. Sonographic guided percutaneous ultrasonic tenotomy and debridement (Tenex) has emerged as a viable treatment option for this chronic condition. This pro- cedure emulsifies the tendinotic/pathologic tissue with a continuous slow saline inflow and then the tissue is selectively suctioned out in a closed collecting system. Tenex is an outpatient procedure and is minimally invasive, requiring little downtime. Prospective and retrospective studies and case reports have been published on this procedure demonstrating positive outcomes [2-5]. There are no established rehabilitation protocols after the Tenex procedure. Thus, we illustrate the rehabilitation protocol that we employed in our athlete that permitted complete return to the rigors of Division 1 athletic competition in just 8 weeks after this intervention.

\section{Patient Information}

L. A. is an 18-year-old male freshman varsity gymnast with lateral elbow pain for 7 months. He was seen for his pre-participation physical examination in July 2018 and reported

*Corresponding author: Bryant J Walrod, M.D. C.A.Q. Department of Family and Community Medicine, Sports Medicine, The Ohio State University, Columbus, USA

Accepted: April 15, 2020

Published online: April 17, 2020

Citation: Walrod B (2020) Rapid and Successful Rehabilitation and Return to Play for a Division 1 Gymnast after Treatment for Recalcitrant Lateral Epicondylosis with Ultrasound Guided Percutaneous Tenotomy. Arch Sports Med 4(1):184-186 
Citation: Walrod B (2020) Rapid and Successful Rehabilitation and Return to Play for a Division 1 Gymnast after Treatment for Recalcitrant Lateral Epicondylosis with Ultrasound Guided Percutaneous Tenotomy. Arch Sports Med 4(1):184-186

Table 1: Rehabilitation protocol.

\begin{tabular}{|c|c|c|c|c|c|c|}
\hline & Week 1 (0-7 days) & $\begin{array}{l}\text { Week } 2 \text { (7-14 } \\
\text { days) }\end{array}$ & $\begin{array}{l}\text { Week } 3 \text { (14-21 } \\
\text { days) }\end{array}$ & $\begin{array}{l}\text { Week } 4 \text { (21-28 } \\
\text { days) }\end{array}$ & $\begin{array}{l}\text { Week } 5 \text { (28-35 } \\
\text { days) }\end{array}$ & $\begin{array}{l}\text { Week } 6 \text { (35-42 } \\
\text { days) }\end{array}$ \\
\hline $\begin{array}{l}\text { Passive } \\
\text { ROM }\end{array}$ & $\begin{array}{l}\text { Elbow flexion \& } \\
\text { Extension - 3' each } \\
\text { Wrist Flexion \& } \\
\text { Extension - 3' each }\end{array}$ & $\begin{array}{l}\text { Same as week } \\
1 \text {, add forearm } \\
\text { pronation and } \\
\text { supination }\end{array}$ & Same as week 2 & Same as week 2 & Same as week 2 & Same as week 2 \\
\hline Active ROM & $\begin{array}{l}\text { On day 4- } \\
\text { Introduce Elbow/ } \\
\text { Wrist flexion \& } \\
\text { extension - 3' } \\
\text { each }\end{array}$ & $\begin{array}{l}\text { Same as week } \\
\text { 1, add forearm } \\
\text { pronation and } \\
\text { supination }\end{array}$ & Same as week 2 & Same as week 2 & Same as week 2 & Same as week 2 \\
\hline Exercises & None & $\begin{array}{l}\text { Isometric wrist } \\
\text { and elbow flexion } \\
\text { and extension }\end{array}$ & $\begin{array}{l}\text { Isometric, } \\
\text { Isotonic, Eccentric } \\
\text { wrist and elbow } \\
\text { extension }\end{array}$ & $\begin{array}{l}\text { Isometric, } \\
\text { Isotonic, Eccentric } \\
\text { wrist and elbow } \\
\text { extension }\end{array}$ & $\begin{array}{l}\text { Begin to } \\
\text { incorporate } \\
\text { joint integrated } \\
\text { movements. }\end{array}$ & $\begin{array}{l}\text { Progress joint } \\
\text { integrated } \\
\text { movements. Begin } \\
\text { to incorporate sport } \\
\text { specific training }\end{array}$ \\
\hline Avoid & Sustained gripping & Sustained gripping & $\begin{array}{l}\text { Exercises that } \\
\text { force non-neutral } \\
\text { grip }\end{array}$ & $\begin{array}{l}\text { Exercises that } \\
\text { force non-neutral } \\
\text { grip }\end{array}$ & $\begin{array}{l}\text { Exercises that force } \\
\text { non-neutral grip }\end{array}$ & None. \\
\hline $\begin{array}{l}\text { Manual } \\
\text { Therapies }\end{array}$ & None & None & None & $\begin{array}{l}\text { Soft tissue } \\
\text { manipulation } \\
\text { or Graston } \\
\text { Technique }\end{array}$ & $\begin{array}{l}\text { Soft tissue } \\
\text { manipulation or } \\
\text { Graston Technique }\end{array}$ & $\begin{array}{l}\text { Soft tissue } \\
\text { manipulation or } \\
\text { Graston Technique }\end{array}$ \\
\hline Post Activity & Ice $20^{\prime}$ & Ice $20^{\prime}$ & Ice $20^{\prime}$ & Ice as needed & Ice as needed & Ice as needed \\
\hline
\end{tabular}

these chronic symptoms. His symptoms were refractory to rest, activity modification, formal physical therapy, acupuncture and an elbow sleeve.

\section{Clinical Findings}

Physical examination revealed full ROM of the elbow and wrist. He had pain at the lateral epicondyle and this was worse with resisted wrist extension, third finger extension and supination. He was neurovascularly intact. The athlete was recommended formal rehabilitation under the guidance of the Athletic Training team at the University. He was also given Naproxen 500 mg twice daily for 2 weeks. He had negative $\mathrm{X}$-rays at this time as well.

\section{Time line}

The student-athlete was compliant with supervised rehabilitation for 8 weeks but his symptoms persisted.

\section{Diagnostic assessment}

An MRI was obtained which revealed thickened and intermediate signal within the common tendon of the forearm extensor muscles compatible with tendinosis. A superimposed partial-thickness tear of the origin of the common forearm extensor was also evident at the posterior margin. Additional treatment options were reviewed with the student athlete including continued rehabilitation, activity modification, autologous blood injection, Platelet Rich Plasma (PRP) injection, and percutaneous tenotomy (Tenex).

\section{Therapeutic intervention}

After a detailed discussion of the treatment options and anticipated rehabilitation and time off of gymnastics, the patient wanted to proceed with Tenex. He underwent the procedure on $09 / 28 / 2018$. His rehabilitation protocol was as follows:

Rehabilitation protocol: The protocol is summarized in Table 1. Day one of the rehabilitation protocol involved changing bandages and passive range of motion (PROM) of elbow flexion and extension. Day four of the program started active range of motion (AROM) of elbow flexion and extension to compliment the PROM. On day seven status- post-procedure the patient began to incorporate wrist flexion and extension as well as forearm pronation and supination to stretching regimen. The patient began isometric strengthening exercises for wrist and elbow flexion and extension on day 10. Exercises were started at low sets (1-2) and repetitions (8-10) with 3 second contraction holds. Rest was encouraged as needed before beginning next repetition or set. On day 16 the patient was instructed to begin adding eccentric and isotonic wrist extension and flexion exercises with the primary goal of building muscle endurance. The patient completed moderate sets (2-4) and high repetitions (10-15). These various types of contractions and exercises were continued for two weeks as weights and frequency progressed slowly.

Once all exercises could be performed in a pain free manner the patient was then introduced to joint integrated movements such as bicep curls, chest press, rows, pull ups and push-ups beginning at five weeks status- post-procedure. All of these movements were completed with a neutral grip of the wrist to avoid stressing the wrist extensors. The patient was also introduced to an endurance type exercises utilizing a five gallon bucket filled with dry rice grains. The exercise 
Citation: Walrod B (2020) Rapid and Successful Rehabilitation and Return to Play for a Division 1 Gymnast after Treatment for Recalcitrant Lateral Epicondylosis with Ultrasound Guided Percutaneous Tenotomy. Arch Sports Med 4(1):184-186

focused on all aspects of wrist range of motion (ROM) and strengthening with 1 minute intervals of turning the rice. The final step of return to sport and activity was to complete handstand progressions and holds. The patient began on the floor with a flattened wrist position for the first few days before he could progress to utilizing the parallettes which would allow for more extension of the wrist in the handstand position. At week 4, soft tissue mobilization techniques were incorporated including the Graston Technique and massage therapies.

The student athlete progressed well. In follow-up on $12 / 05 / 2018$ he reported no pain at rest or with full activity and his strength and ROM were normal. He was able to return to full Division 1 athletic gymnastic practice on $12 / 05 / 218$ and then competed in the season opening competition on $01 / 12 / 2019$. He continues to participate in $\mathrm{Di}$ vision 1 gymnastics through the 2020 season with no limitations from this lateral elbow pain.

\section{Discussion}

This case illustrating percutaneous tenotomy for chronic lateral epicondylosis is unique for 2 reasons. First, we describe successful return to high level competition in the form of Division 1 Athletics for chronic and refractory lateral elbow pain. Second, we describe a specific rehabilitation protocol that allowed for rapid return to full practice in 2 months. Typically, patients are given activity and lifting restrictions for about 6 weeks following this procedure but these can vary depending upon physician preference. Often, no formal rehabilitation guidelines are provided. When given, recommendations are often vague with no strong recommendation of when the patient can safely return to activities such as ADLs. There are no specific guidelines with respect to return to high level activities like Division 1 athletics. There are no published standard of care guidelines on specific rehabilitation protocols after the Tenex procedure from the manufacturer nor has such recommendations appeared in the literature.
In addition, often the outcomes measures in the published studies on Tenex for lateral epicondylosis are VAS and Q- DASH scores and patient satisfaction. Published studies on the Tenex procedure have not reported on outcomes measuring return to high level activity such as Division 1 athletics.

Secondary to our successful and rapid treatment success to high level activities, clinicians should consider employing the treatment and rehabilitation protocols illustrated above after percutaneous tenotomy for recalcitrant lateral epicondylosis. Further studies will be needed to determine if similar treatment protocols will be applicable to additional indications for the Tenex procedure such as medial epicondylosis, patella tendinosis, gluteal tendinosis and achilles tendinosis.

\section{Clinical Bottom Line}

There are no established guidelines or protocols to guided clinicians or patients after undergoing a percutaneous tenotomy. In this case report, we outline a specific rehabilitation protocol that resulted in rapid and complete return to high level sporting activities.

\section{References}

1. RP Nirschl, ES Ashman (2003) Elbow tendinopathy: Tennis elbow. Clin Sports Med 22: 813-836.

2. Koh JS, Mohan PC, Howe TS, et al. (2013) Fasciotomy and surgical tenotomy for recalcitrant lateral elbow tendinopathy: Early clinical experience with a novel device for minimally invasive percutaneous microresection. Am J Sports Med 41: 636-644.

3. Morrey B (2013) Ultrasound percutaneous tenotomy for epicondylitis. Techniques in Shoulder and Elbow Surgery 14: 51-58.

4. Barnes DE, Beckley JM, Smith J (20145) Percutaneous ultrasonic tenotomy for chronic lateral elbow tendinosis: A prospective study. J Shoulder Elbow Surg 24: 67-73.

5. Boden AL, Scott MT, Dalwadi PP, et al. (2019) Platelet rich plasma versus Tenex in the treatment of medial and lateral epicondylitis. J Shoulder Elbow Surg 28: 112-119.

DOI: $10.36959 / 987 / 249$

Copyright: (C) 2020 Walrod B. This is an open-access article distributed under the terms of the Creative Commons Attribution License, which permits unrestricted use, distribution, and reproduction in any medium, provided the original author and source are credited. 